\section{Adenomyomatous hyperplasia of the lower bile duct mimicking a papillary bile duct tumor}

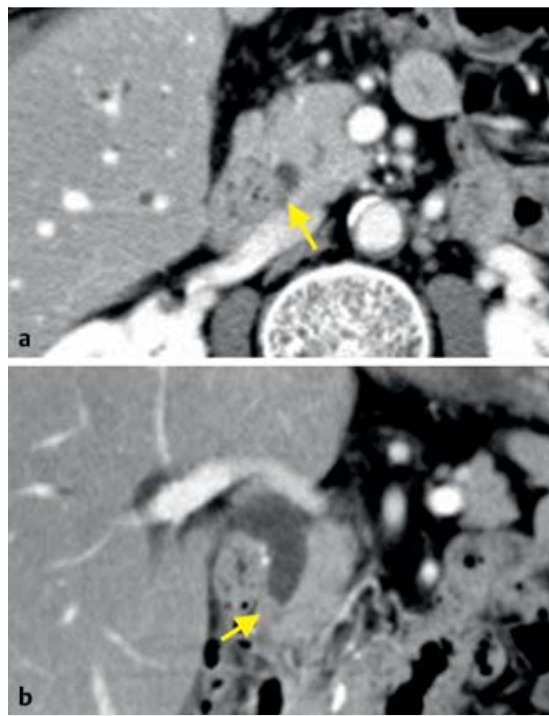

Fig. 1 Abdominal contrast-enhanced computed tomography (CT) scan showing a mass lesion (yellow arrows) in the lower bile duct: $\mathbf{a}$ in the axial plane; $\mathbf{b}$ in the coronal plane.

Adenomyomatous hyperplasia is an extremely rare benign lesion of the hepatobiliary tract, including the ampulla of Vater, with most cases described in the gallbladder [1 -4]. However, its importance lies in its ability to mimic bile duct tumors $[1,2]$. A 66-year-old man without jaundice was found to have dilatation of the common and intrahepatic bile ducts on ultrasonography performed during ambulant treatment of diabetes mellitus and hypertension. An enhanced computed tomography (CT) scan showed a mass lesion in the lower bile duct ( $\bullet$ Fig. 1). Endoscopic ultraso- nography (EUS) revealed a hypoechoic lesion in the bile duct portion of the ampulla of Vater, with the lesion also extending to the lower bile duct ( $\bullet$ Fig. 2 a), suggesting a papillary bile duct tumor. EUS-guided fine needle aspiration (EUS-FNA) of the bile duct lesion was therefore performed, and microscopic examination showed no apparent malignant cells ( $\bullet$ Fig. 2 b).

Endoscopic retrograde cholangiography (ERCP) showed an irregular stricture in the lower bile duct ( $\bullet$ Fig. 3 a), while intraductal ultrasound and peroral cholangioscopy by SpyGlass demonstrated that this stricture was caused by a papillary mass ( Fig. 3 b, c; $\bullet$ Video 1 ). The endoscopic transpapillary biopsy specimen of this papillary mass showed no apparent malignant cells ( Fig.4); however, the possibility of a tumor could not be completely excluded and we therefore performed pancreatoduodenectomy. Histologically, the bile duct epithelium was structurally papillary, and mildly atypical glands and hyperplasia of smooth muscle fibers were observed ( $\bullet$ Fig.5). The papillary bile duct lesion was finally diagnosed as adenomyomatous hyperplasia.

No specific imaging features permit the reliable differentiation of adenomyomatous hyperplasia from tumor; however, a possible diagnosis of adenomyomatous hyperplasia should be kept in mind in a patient with bile duct stricture. For accurate preoperative diagnosis, it is important to obtain enough biopsy specimens confirming hyperplastic glands surrounded by smooth muscle fibers.
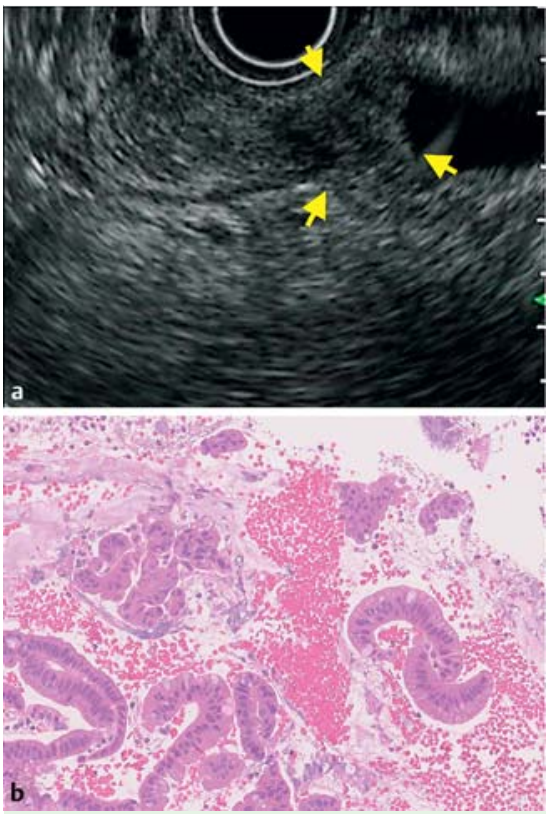

Fig. 2 The lesion in the lower bile duct was shown: a on linear array endoscopic ultrasonography (EUS), to be a 14.9-mm hypoechoic mass (yellow arrows); $\mathbf{b}$ on histology from an EUS-guided fine needle aspiration (FNA), to have no apparent malignant cells (hematoxylin and eosin [H\&E] stain, original magnification $\times 200$ ).

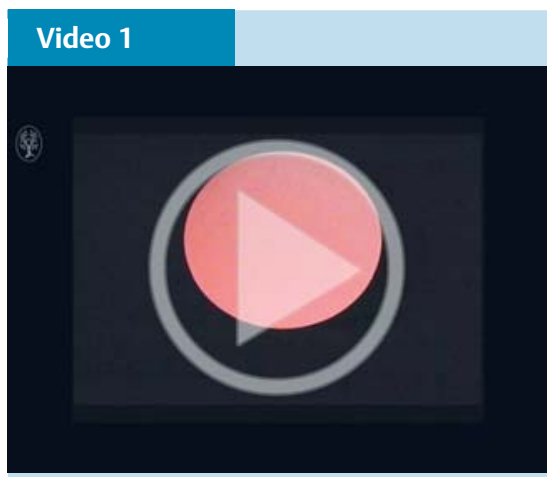

Peroral cholangioscopy by SpyGlass showing that the stricture in the lower bile duct was caused by a papillary mass.
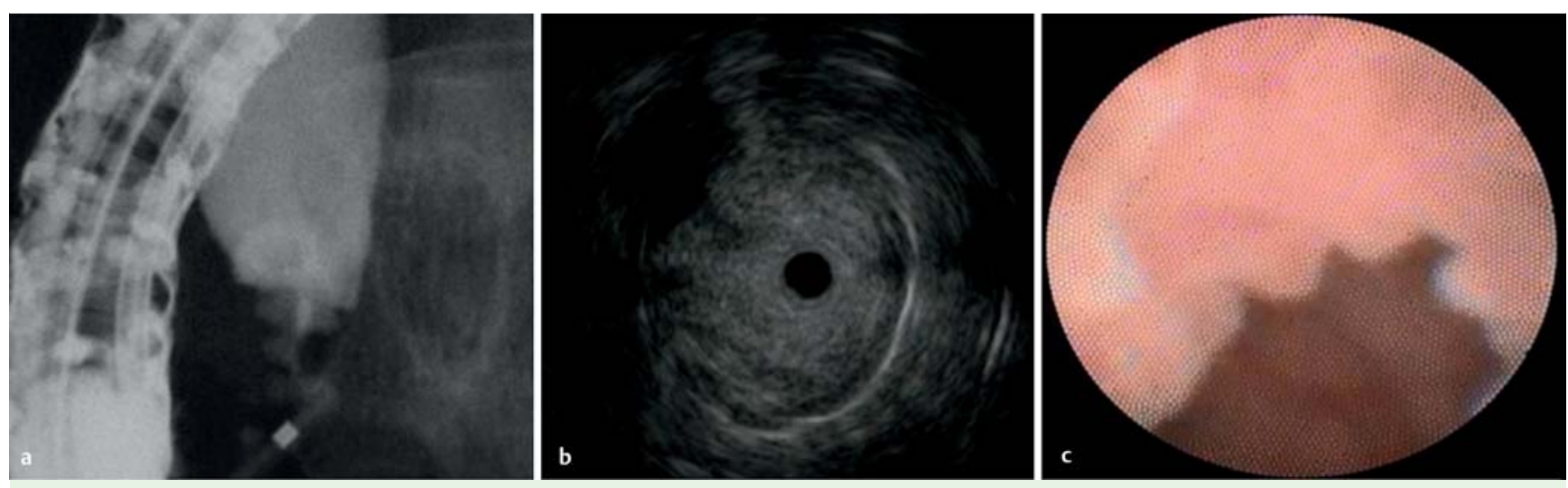

Fig. 3 Appearance of the lesion on: a endoscopic retrograde cholangiography showing an irregular stricture at the lower bile duct; $\mathbf{b}$ intraductal ultrasound; and $\mathbf{c}$ peroral cholangioscopy by SpyClass showing that the stricture was caused by a papillary mass. 


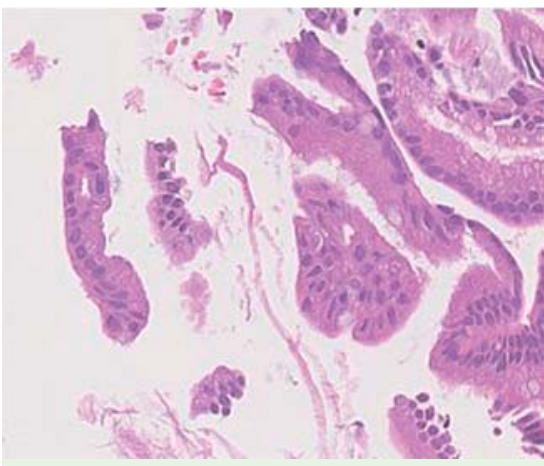

Fig. 4 Histological appearance of the endoscopic transpapillary biopsy taken from the papillary mass showed no apparent malignant cells (hematoxylin and eosin [H\&E] stain, original magnification $\times 200$ ).

\section{Endoscopy_UCTN_Code_CCL_1AZ_2AC}

\section{Competing interests: None}

\section{Yoshikuni Nagashio ${ }^{1}$, Terumasa Hisano', Yoshifusa Aratake', Eiji Tsujita², Fumiyoshi Fushimi ${ }^{3}$, Kenichi Taguchi ${ }^{3}$, Masayuki Furukawa ${ }^{1}$}

${ }^{1}$ Department of Hepato-Biliary-Pancreatology, National Kyushu Cancer Center, Fukuoka, Japan

2 Department of Hepato-Biliary-Pancreatic Surgery, National Kyushu Cancer Center, Fukuoka, Japan

${ }^{3}$ Department of Pathology, National Kyushu Cancer Center, Fukuoka, Japan

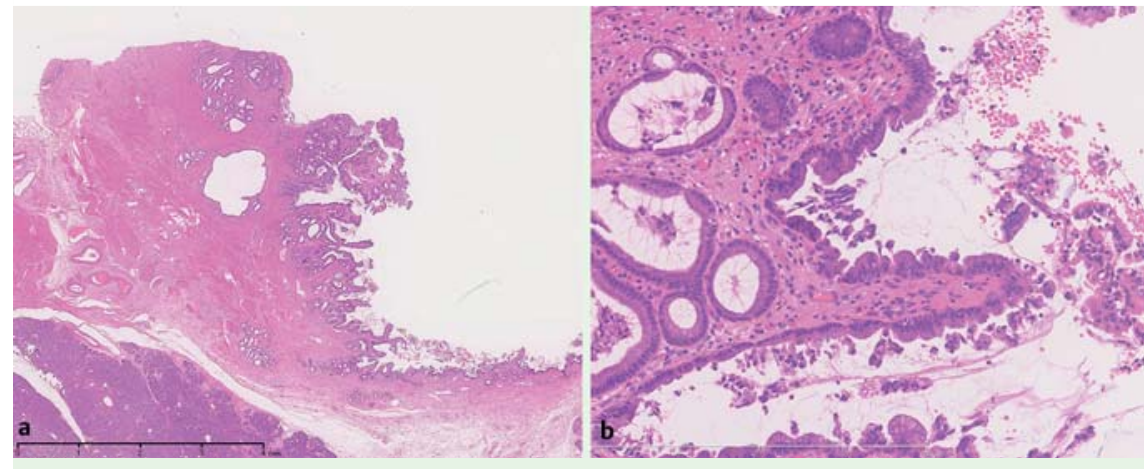

Fig. 5 Histological appearance of the hematoxylin and eosin (H\&E)-stained specimen that was resected at pancreatoduodenectomy showed papillary hyperplasia of the surface mucosa and dilated glands surrounded by hyperplastic smooth muscle fibers at original magnifications of: $\mathbf{a} \times 12.5$; $\mathbf{b} \times 200$.

\section{References}

1 Imai S, Uchiyama S, Suzuki T et al. Adenomyoma of the common hepatic duct. J Gastroenterol 1995; 30: $547-550$

2 Numata M, Morinaga S, Watanabe T et al. A case of adenomyomatous hyperplasia of the extrahepatic bile duct. Case Rep Gastroenterol 2011; 5: 457-462

3 Handra-Luca A, Terris B, Couvelard A et al. Adenomyoma and adenomyomatous hyperplasia of the Vaterian system: clinical, pathological, and new immunohistochemical features of 13 cases. Mod Pathol 2003; 16: $530-536$

4 Albores-Saaredra J, Henson DE, Klimstra DS. Tumors of the gallbladder, extrahepatic bile ducts, and Vaterian system (AFIP atlas of tumor pathology, series IV), volume 23 . Rockville, Maryland: American Registry of Pathology; 2015

\section{Bibliography}

Dol http://dx.doi.org/

10.1055/s-0042-115941

Endoscopy 2016; 48: E311-E312

(c) Georg Thieme Verlag KG

Stuttgart · New York

ISSN 0013-726X

\section{Corresponding author} Yoshikuni Nagashio, MD, PhD

Department of Hepato-Biliary-Pancreatology

National Kyushu Cancer Center

3-1-1 Notame, Minami-ku

Fukuoka 811-1395

Japan

Fax: +81-92-5428503

pdhtn413@yahoo.co.jp 